\title{
INEQUALITIES IN HEALTH STATUS DEPENDING ON SOCIO-ECONOMIC SITUATION IN THE EUROPEAN COUNTRIES
}

\author{
Viera Pacáková, Lucie Kopecká
}

\section{Introduction}

Quality health care system is a priority for citizens of each country and a precondition for economic prosperity. The public health systems in many counties bear the huge burden of treatment of serious diseases, particularly cardiovascular diseases and cancer. Cancer, heart disease, diabetes, respiratory, mental and other chronic diseases represent great suffering to citizens and represent a huge cost to society and the economy. It is estimated that they will cost the global economy around $€ 22.5$ trillion between 2012 and 2030 (EU, 2013).

Mortality statistics show that cardiovascular disease (CVD) remains the most common cause of death in European countries. Each year cardiovascular disease causes 3.9 million deaths in Europe and over 1.8 million deaths in the European Union (EU), so CVD accounts for $45 \%$ of all deaths in Europe and $37 \%$ of all deaths in the EU. In 2015, there were just under 11.3 million new cases of CVD in Europe and 6.1 million new cases of CVD in the EU. In 2015, more than 85 million people in Europe were living with CVD and almost 49 million people were living with CVD in the EU. Overall CVD is estimated to cost the EU economy $€ 210$ billion a year. Of the total cost of CVD in the EU, around $53 \%$ ( $€ 111$ billion) is due to health care costs, $26 \%$ ( $€ 54$ billion) to productivity losses and $21 \%$ ( $€ 45$ billion) to the informal care of people with CVD (Wilkins et al., 2017).

Cancer is the second leading cause of death worldwide. In 2015, there were 17.5 million cancer cases worldwide and 8.7 million deaths. Between 2005 and 2015, cancer cases increased by $33 \%$, with population aging contributing $16 \%$, population growth $13 \%$, and changes in agespecific rates contributing $4 \%$. Cancer is the main cause of premature death in 28 of the 53 countries in the European Region, and is predicted to further increase by 2020 (Fitzmaurice et al., 2017).
Disease mortality patterns vary widely across the European Region, between countries and by age and gender. About 30\% of deaths occur before the age of 65 . The European Region is on track to achieve the target to reduce premature mortality from cardiovascular diseases, cancer, diabetes and chronic respiratory diseases. Nevertheless, levels of alcohol consumption, tobacco use and overweight and obesity, which are among the major risk factors for premature mortality, remain alarmingly high. The European Region has the highest levels of alcohol consumption and tobacco use in the world, and ranks only slightly behind the Region of the Americas in rates of overweight and obesity. The prevalence of overweight and obesity in European countries ranges from $45 \%$ to $67 \%$ (WHO, 2016). By OECD (2015) most countries do not perform well for at least one or more indicators of risk factors to health, whether that is the proportion of their population smoking tobacco, alcohol consumption, or overweight and obesity among children and adults.

\section{Theoretical Background}

The main social determinants of health are synonymous with the welfare resources that are necessary to lead a good life. These include economic resources, working conditions, housing conditions, education and knowledge. The unique analyses presented in Lundberg et al. (2016) indicate that lower poverty is associated with lower mortality, both among young children and adults.

There are a number of major studies which have demonstrated a clear link between socioeconomic background (such as income or occupation) and health. Research into income and health has largely focused on the issue of whether income inequality as such influences health, independently of absolute levels of 
income or the proportion of poor people. There are many studies, and how to interpret their findings is highly debated. Wilkinson's (1992) cross-country work, found a relationship across the states between various measures of income inequality and age-adjusted all-cause mortality, as well as a number of other measures, including infant mortality rates, deaths from cancer, coronary heart disease, and homicide, as well as disability, low birth weight, and crime. Wilkinson and Pickett (2006) argue that there is a relationship between income inequality and social problems. The book of Wilkinson and Pickett (2009), which attracted a lot of attention, called for a more careful analysis of the consequences of rising income inequality.

The European Union has paid increasing attention to health inequalities following the publications Improving Health for all EU Citizens (European Union, 2013) and Sustainable Development Goals from an EU perspective (Eurostat, 2017). In this context, a number of publications working papers, and final reports have been produced by the European Commission.

Reports of European Commission Joint Research Centre constitutes the deliverable of a comprehensive series of studies initiated by the European Commission on the social and economic challenges associated with rising income inequalities. The study of author's d'Hombres, Elia, and Weber (2013) provides a multivariate analysis of the effect of income inequality on three important social outcomes, i.e. health, social capital, and happiness. This study suggests that the data analysis cannot confirm the hypothesis of a strong and significant effect of income inequality on health. However, the analysis shows that income inequality has a potential damaging effect on trust in Europe.

On the contrary, in Eurostat Methodologies and Working papers (2010) there is an evidence of income-related inequalities in health for all the countries analysed, although they present a heterogeneous pattern over time.

The literature outside of economics has documented many hundreds of cases of a positive correlation between health and some measure of socioeconomic status; see (Marmot et al., 1984) and the more general discussions in Marmot (2002). The paper of Deaton (2013) explores the theoretical basis and empirical evidence for a connection between inequality and health, among poor as well as rich countries and discusses a number of other theoretical links between inequality and health.

The relationship between income and health is complicated and certainly not a simple issue. Recent years have witnessed an increase in attempts to more systematically study welfare states and public health. Several systematic reviews of population health, health inequalities and welfare state have been published. Beckfield and Krieger (2009) reviewed 45 studies addressing the relationship between determinants of social policy and health inequities.

Several interesting publications by Czech and Slovak authors in recent years also point to the possible socio-economic cause of considerable differences in the functioning of public health systems, health care and the health status of European citizens: (Jindrová, 2013; Šoltés \& Gavurová, 2014; Gavurová \& Vagasová, 2016; Pacáková et al., 2016; Pacáková \& Papoušková, 2016; Clark et al., 2017; Kopecká \& Jindrová, 2017).

Just like the socio-economic situation is important for good health of the population in individual countries, the health status of the population is a significant indicator of functioning of the state economy as well.

\section{Objectives, Data and Methods}

The goal of this article is to assess and quantify inequalities in health status of inhabitants depending on socio-economic situation in European countries based on selected social and health indicators in two different periods. The earlier period is the year 2000 , later period is the year 2015 or the most recent years.

The results of the analysis based on multidimensional statistical methods should give an answer to the question as to whether and how strong the socio-economic situation in the countries of Europe affects the health status of the population and how the situation has changed over the course of 15 years. During these 15 years, major political changes have taken place in Europe, and several countries, especially the former socialist countries have become members of the OECD and the EU, and it is therefore undeniably interesting to see how these developments have affected the social situation, health status and their relationship in the European region. The aim is also to verify the reduction of disparities in health status 
dependent on social situation in the European countries. To achieve the stated objectives, it is necessary to have a suitable data. There are collected and regularly updated on-line published a few databases about health, health care and health status on regional, national, EU member countries, OECD countries and on the world level. As well as on all these levels there are available many social indicators. These databases contain mostly time-space series of reporting aggregate data. Databases are used as the basis for many publications containing the key indicators of health or social situation of countries or regions and their comparison in the form of tables, graphs and by various forms of data visualization. They are, for example, annual publications as statistical yearbooks, the European health or social reports, series of key statistical publications OECD Health at a Glance (four editions) and eight editions of OECD Society at a Glance. The basic source of health data is the database of the World Health Organization (WHO) for Europe.

Throughout this article we use a few data sources chosen with consideration of data quality, date of the most recent update, and coverage of the most countries of European region. The OECD health database OECD
Health Statistics 2016 (OECD, online) offers the most comprehensive source of comparable statistics covering all aspects of health systems for the 35 OECD member countries. The OECD publishes online also social data and indicators suitable for the purposes of our analysis. The problem is a missing data for some countries which can be partially supplemented by the database of World Health Organization (WHO, online) or Eurostat. In accordance with the stated objectives we have chosen these 15 variables in Tab. 1.

These indicators together characterize the quality of life in terms of social situation and state of health of citizens. Life expectancy is undoubtedly the best indicator of quality of life. The social situation in each country is clearly influenced by income level and by unemployment rate. Given the gravity mainly cardiac and oncological diseases in our opinion the standardized mortality rates for these illnesses can be considered as the most accurate indicators of the population state of health. Age-standardised death rates per 100,000 population for selected causes are calculated by the OECD Secretariat, using the total OECD population for 2010 as the reference population. The age-standardised death rates

\section{Tab. 1: Selected variables}

\begin{tabular}{c|l} 
Abbreviation & \multicolumn{1}{|c}{ Variable description } \\
\hline D1 & life expectancy at birth \\
\hline D2 & life expectancy at age 65 \\
\hline M1 & mortality neoplasms deaths per 100,000 total (standardised rates) \\
\hline M2 & malignant neoplasms deaths per 100,000 total (standardised rates) \\
\hline M3 & trachea, bronchus, lung cancer deaths per 100,000 total (standardised rates) \\
\hline M4 & malignant neoplasms colon and rectum deaths per 100,000 total (standardised rates) \\
\hline M5 & malignant neoplasms female breast deaths per 100,000 females (standardised rates) \\
\hline M6 & malignant neoplasms of cervix uteri deaths per 100,000 females (standardised rates) \\
\hline M7 & malignant neoplasms of stomach deaths per 100,000 total (standardised rates) \\
\hline C1 & ischemic heart diseases deaths per 100,000 total (standardised rates) \\
\hline C2 & cerebrovascular diseases deaths per 100,000 total (standardised rates) \\
\hline S1 & unemployment rate \\
\hline S2 & long-term unemployment rate \\
\hline S3 & median income 2015 (EUR) \\
\hline S4 & health expenditure per capita (EUR)
\end{tabular}


are necessary for comparing the level of mortality across countries and over time, since they take into account the differences in age structure of the populations.

According to the above mentioned goals of the article we have used following multidimensional statistical methods on a selected set of health and social indicators.

\subsection{Factor Analysis}

This frequently used statistical method is described in detail in many foreign and domestic publications, for example (Hebák et al., 2007; Řezánková et al., 2009; Stankovičová \& Vojtková, 2007; Hair et al., 2007; Johnson \& Wichern, 2007). Its application is not possible without using any statistical software package. We have used the statistical software Statistica 12, licensed from the University of Pardubice. This article contains only the information that is necessary for understanding of computer output of factor analysis.

Factor analysis (FA) is a statistical approach that can be used to analyse interrelationships among a large number of variables and to explain these variables in terms of their common underlying factors. The general purpose of factor analytic techniques is to find a way of condensing (summarizing) the information contained in a number of original variables into a smaller set of new composite factors with a minimum loss of information. Numerous variations of the general factor model are available. The two most frequently employed approaches are principal component analysis and common factor analysis. The component model is used when the objective is to summarize most of the original information (variance) in a minimum number of factors. The Scree Plot can be very helpful in determining the number of factors to extract, because displays the eigenvalues associated with a component or factor in descending order versus the number of the factors.

An important concept in factor analysis is the rotation of factors. In practice, the objective of all methods of rotation is to simplify the rows and columns of the factor matrix to facilitate interpretation. The Varimax criterion centres on simplifying the columns of the factor matrix. With the Varimax rotation approach, there tend to be some high loadings (i.e., close to -1 or +1 ) and some loadings near 0 in each column of the matrix. The factor loadings show the correlation between the original variables and the factors and they are the key to understanding the nature of a particular factor. The Factor Scores in output of Factor analysis procedure display the values of the rotated factor scores for each of $n$ cases, in our analysis for each of 22 European countries. Factor score show where each country falls with respect to the extracted factors.

\subsection{Cluster Analysis}

The Cluster analysis procedure is designed to group observations (countries) into clusters based upon similarities between them. There are number of different algorithms provided for generating clusters and are described in detail in many statistical publications. In addition to those listed in section 2.1. for example in (Řezánková, 2009; Labudová et al., 2010). We have used the agglomerative algorithm, beginning with separate clusters for each observation or variable and then joining clusters together based upon their similarity. To form the clusters, the procedure began with each observation in a separate group. It then combined the two observations which were closest together to form a new group. After recomputing the distance between the groups, the two groups then closest together are combined. This process is repeated until only one group remained. The results of the analysis are displayed in a dendogram.

The distance between two observations we calculate by Euklidian distance, defined as

$$
D_{E}\left(x_{i}, x_{j}\right)=\sqrt{\sum_{l=1}^{m}\left(x_{i l}-x_{j l}\right)^{2}}
$$

and distance between two clusters by Ward's method. Ward's method defines the distance between two clusters in terms of the increase in the sum of squared deviations around the cluster means that would occur if the two clusters were joined. The results of the analysis are displayed in several ways, including a dendrogram. Working from the bottom up, the dendrogram shows the sequence of joins that were made between clusters. Lines are drawn connecting the clustered that are joined at each step, while the vertical axis displays the distance between the clusters when they were joined. 


\subsection{Multidimensional Comparative Analysis}

Multidimensional comparative analysis deals with the methods and techniques of comparing multi-feature objects, in our case selected European countries. One of the particular problems here is that of establishing a linear hierarchy (linear ordering) among a set of objects in a multidimensional space of features, from the point of view of certain characteristics which cannot be measured in a direct way (the level of socio-economic development, the standard of health care, health status, etc.). We can also consider them as methods of linear ordering of multidimensional objects using a synthetic variable created from the original variables. The synthetic variable allows to replace the whole set of variables into one aggregated variable. Number of applications of these methods can be found in the publications of Polish statistics and econometrics, for example (Grabinski et al., 1993; Sokolowski, 1999; Kuc, 2012). Examples of their use in publications of Czech authors are (Pacáková et al., 2016; Pacáková \& Papoušková, 2016; Kopecká \& Jindrová, 2017).

At the beginning of the analysis, the type of each variable must be defined. It is necessary to identify whether the high values of a variable positively influence the analysed processes (such variables are called stimulants) or whether their low values are favourable (these are called destimulants). The original variables are usually expressed in different units of measurement and must be standardised to create a synthetic (aggregate) variable. A number of formulas are used for standardisation.

$$
\begin{aligned}
& b_{i j}=\frac{x_{i j}}{x_{\max , j}} \cdot 100 \\
& b_{i j}=\frac{x_{\min , j}}{x_{i j}} \cdot 100
\end{aligned}
$$

We have used formula (2) for stimulants and formula (3) for destimulants (Stankovičová \& Vojtková, 2007).

The synthetic variable allows to replace the whole set of origin standardised variables into one aggregated variable. There is variety of methods for creating a synthetic variable. In this paper the synthetic variable for $i$-th country, $b_{\mathrm{i}, \mathrm{j}}, j=1,2, \ldots, k$, has been calculated as the average of the values $b_{i, j}, j=1,2, \ldots, k$ where the subscript $i$ stands for the country number, and the subscript $j$ stands for the variable number.

The matching in the order of the countries by each pair of synthetic variables can be quantify using Spearman's rank correlation coefficient, which for any two variables $X, Y$ can be calculated according to the formula

$$
r_{S}=1-\frac{6 \cdot \sum_{i=1}^{n}\left(i_{x}-i_{y}\right)^{2}}{n \cdot\left(n^{2}-1\right)}
$$

where $i_{x}$ a $i_{y}$ are the ranks of the values of the variables $X, Y$. These correlation coefficients range between -1 and +1 and inform about degree of compliance of the ranks.

\section{Results and Discussion}

\subsection{Factor Analysis Results}

The purpose of the analysis is to obtain a small number of factors which account for most of the variability of the 15 original variables which characterize the social and health situation in 22 European countries in the years 2000 and 2015. In both time periods three factors have been extracted, since three factors have eigenvalues greater than or equal to 1.0. We have used scree plots to visually assess which factors explain most of the variability in the data (Fig. 1). Together they account for $85.14 \%$ of the variability in the original data in the year 2000 and $84.9 \%$ in the year 2015 .

The factorability tests provide indications of whether or not it is likely to be worthwhile attempting to extract factors from a set of variables. The $\mathrm{KMO}$ statistic provides an indication of how much common variability is present. For factorization to be worthwhile, KMO should normally be at least 0.6. Since $\mathrm{KMO}=0.6728$ in the year 2000 and $\mathrm{KMO}=0.7180$ in the year 2015 , factorization is likely to provide interesting information about any underlying factors.

Interpretation of the three extracted factors is based on the significant higher loadings after Varimax rotation in Tab. 2. Factor $1(F 1)$, which explains $54.30 \%$ of the total variability in the data in the year 2000, has seven significant loadings, four with positive signs with variables 
a) year 2000

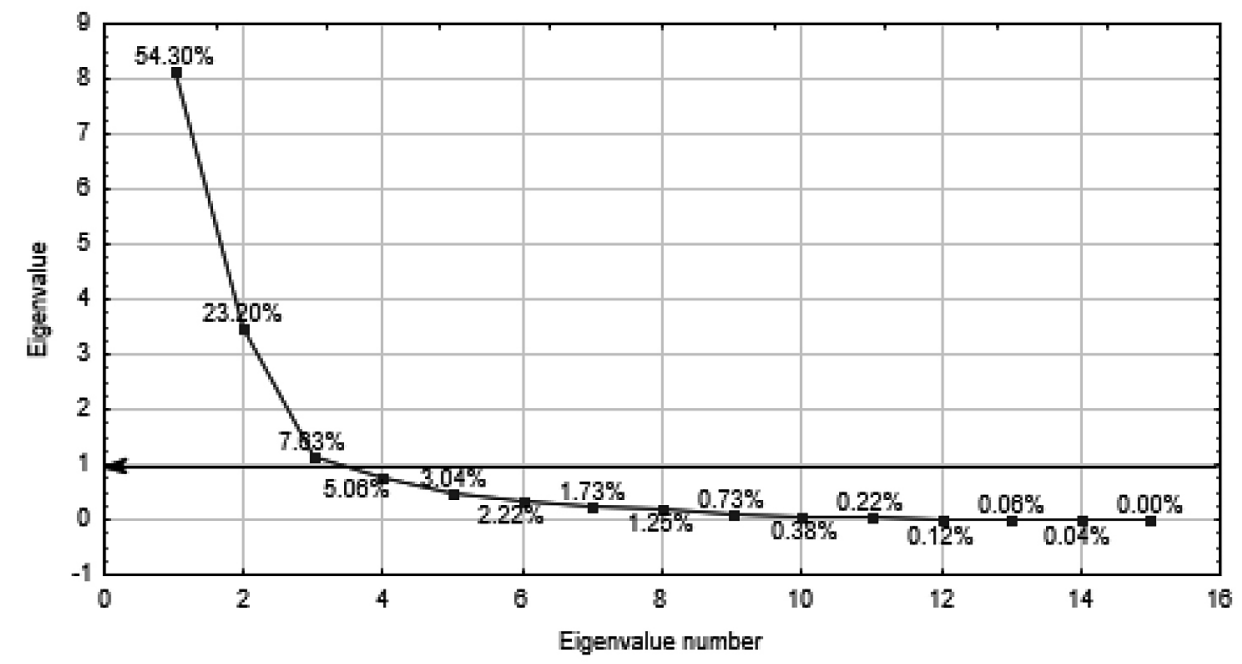

Source: autors' calculations

b) year 2015

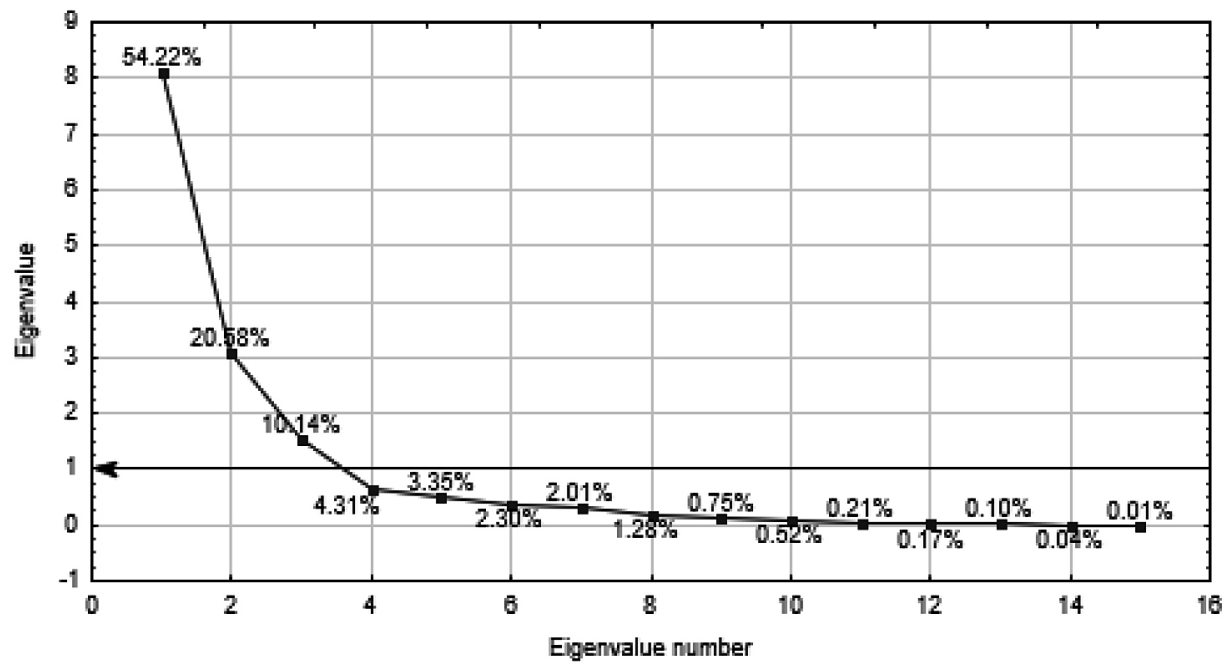

Source: autors' calculations 
Tab. 2: Factor loading matrix after Varimax rotation (output from Statistica 12)

\begin{tabular}{|c|c|c|c|c|c|c|}
\hline \multirow{2}{*}{ Variables } & \multicolumn{3}{|c|}{2000} & \multicolumn{3}{|c|}{2015} \\
\hline & Factor 1 & Factor 2 & Factor 3 & Factor 1 & Factor 2 & Factor 3 \\
\hline$D 1$ & 0.723591 & 0.533822 & 0.327123 & 0.911685 & 0.268768 & -0.109530 \\
\hline$D 2$ & 0.626332 & 0.653717 & 0.273953 & 0.886213 & 0.320793 & -0.213974 \\
\hline$M 1$ & -0.199388 & -0.951496 & -0.058033 & -0.633390 & -0.747796 & 0.099652 \\
\hline M2 & -0.241100 & -0.947527 & -0.071756 & -0.652179 & -0.732677 & 0.068384 \\
\hline M3 & -0.033685 & -0.879103 & -0.114638 & -0.232801 & -0.862376 & 0.009522 \\
\hline M4 & -0.305284 & -0.816219 & 0.048601 & -0.698268 & -0.478341 & 0.080283 \\
\hline M5 & 0.168105 & -0.776917 & 0.349111 & 0.031354 & -0.905849 & 0.074157 \\
\hline M6 & -0.617001 & -0.541077 & -0.352264 & -0.901124 & -0.232036 & 0.077416 \\
\hline M7 & -0.901860 & -0.027739 & -0.172946 & -0.724397 & -0.044531 & -0.317714 \\
\hline$C 1$ & -0.247578 & -0.588332 & -0.344805 & -0.838472 & -0.111208 & 0.162655 \\
\hline$C 2$ & -0.915534 & -0.122756 & -0.119993 & -0.755785 & -0.226561 & -0.399358 \\
\hline S1 & -0.230683 & 0.029754 & -0.962397 & 0.104444 & 0.168504 & -0.942553 \\
\hline$S 2$ & -0.266868 & -0.023415 & -0.922621 & 0.021852 & 0.052592 & -0.962215 \\
\hline S3 & 0.741487 & 0.145533 & 0.567469 & 0.737306 & 0.070056 & 0.563477 \\
\hline S4 & 0.705502 & 0.229807 & 0.605076 & 0.762794 & 0.047700 & 0.525403 \\
\hline
\end{tabular}

Source: own calculation

$D 1, D 2, S 3, S 4$ and three with negative signs with variables $M 6, M 7, C 2$. Therefore, this factor can be interpreted as a general factor of social and health situation. The higher the value $F 1$, the better are the social conditions and the state of health in the selected European countries in the year 2000. Also in 2015, F1 can be considered as a general factor of social and health situation, explaining $54.22 \%$ of the variability of all original variables. Unlike in $2000 \mathrm{~F} 1$ strongly correlates with up to nine original variables, where factor loadings with the social indicators $D 1, D 2, S 3, S 4$ are positive and with indicators of health status M4, M6, M7, C1, C2 the signs are negative. The high values of $F 1$ also in year 2015 indicate a high level of social situation and state of health in the selected European countries.

Factor F2 in the both years with respect to the values of factor loadings can be interpreted as factors of mortality for serious diseases. In both periods this factor strongly correlated with indicators of mortality from cancers $M 1$, M2, M3 and M5 in (Tab. 2). The values of factor loadings with the variables $M 1, M 2$, M3 decreased in 2015 compared to the year 2000 , but the negative correlation with the $M 5$ indicator increased from -0.7779 to -0.9058 . In 2000, factor F2 was strongly correlated with indicators D2 and M4. In 2015, the values of factor $F 2$ are not affected by life expectancy at age $65(D 2)$ and by malignant neoplasms colon and rectum deaths (M4). Its values are in the year 2015 affected only by indicators of mortality from cancer and the proportion of explained variability of the original variables decreased from $23.20 \%$ to $20.58 \%$ compared with the year 2000 .

Factor F3 in both years can be interpreted consistently as unemployment factors due to the high negative values of factor loadings with indicators of unemployment $S 1, S 2$. Its low values indicate high unemployment. In the year 2000 , the percentage of variability of the original variables explained by this factor was $7.64 \%$, in 2015 the share of the explained variability increased to $10.14 \%$. 
Location of selected European countries according to F1, F2 in the year 2000 (output from Statistica 12)

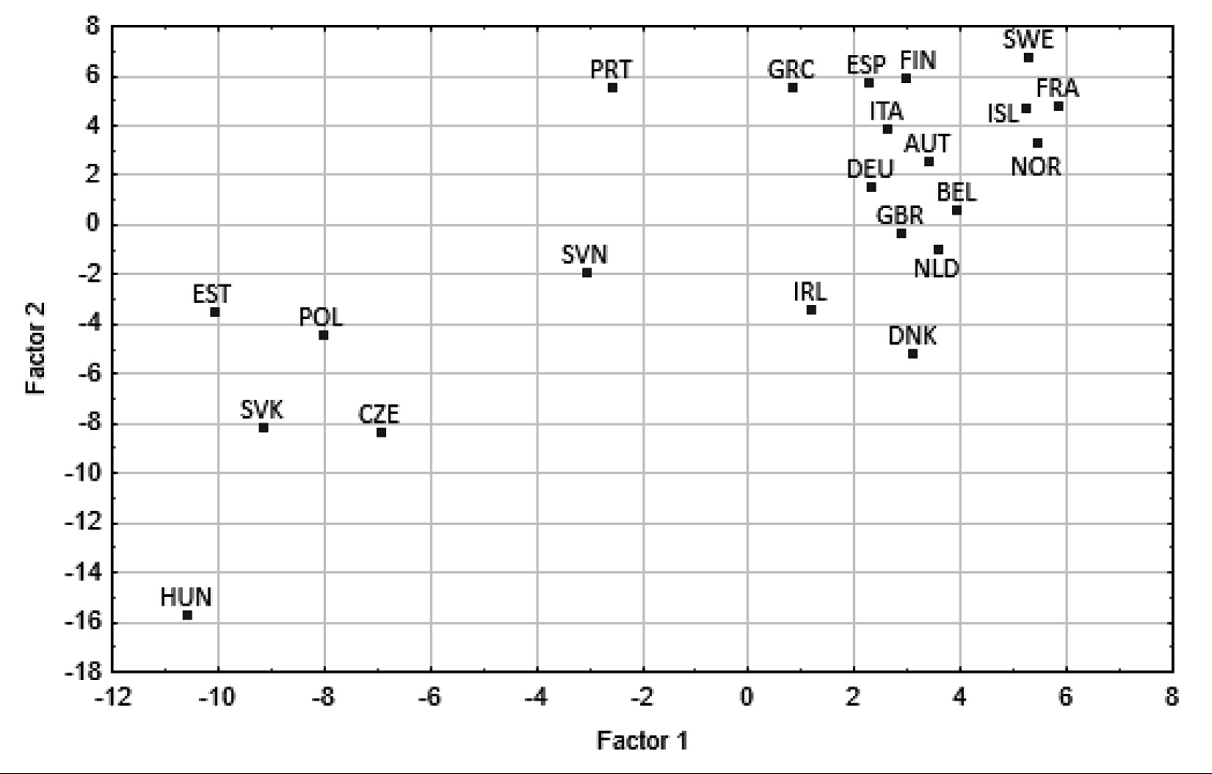

Source: own calculation (output from Statistica 12)

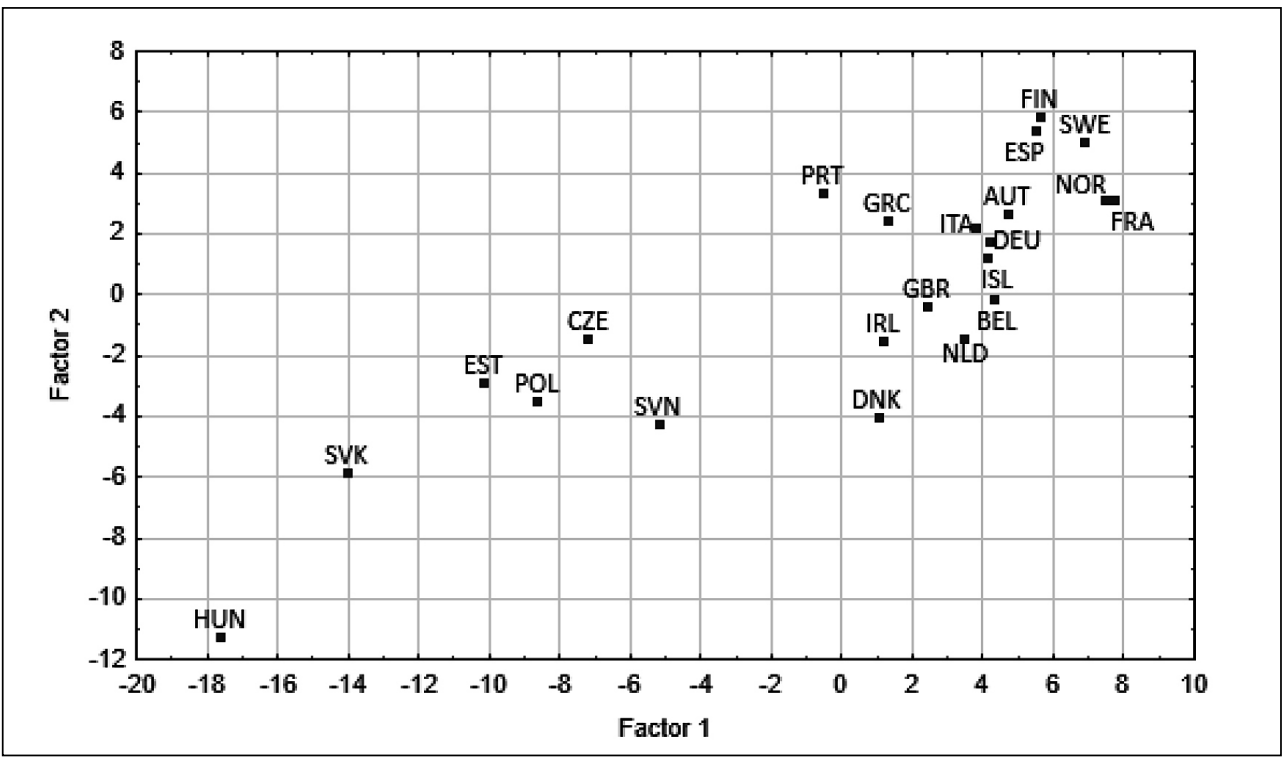

Source: own calculation 
Location of selected European countries according to $F 3, F 2$ in the year 2000 (output from Statistica 12)

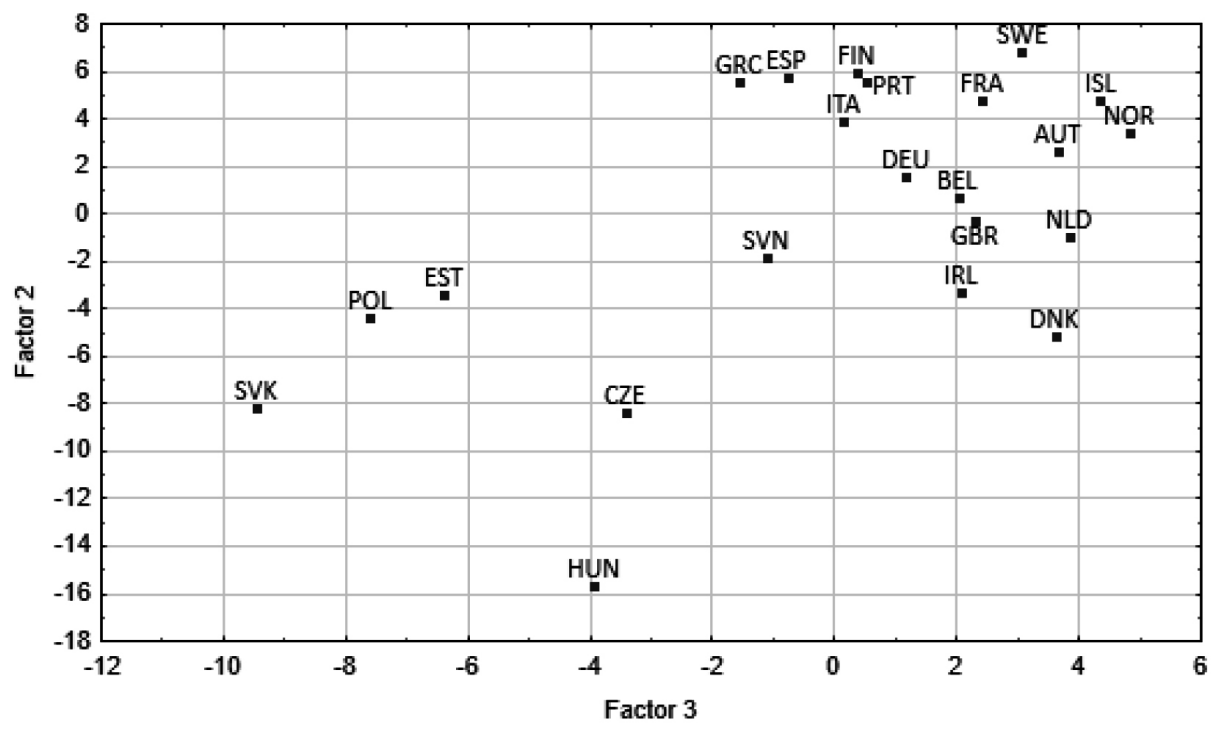

Source: own calculation

Location Selected European Countries according to F3, F2 in the year 2015 (output from Statistica 12)

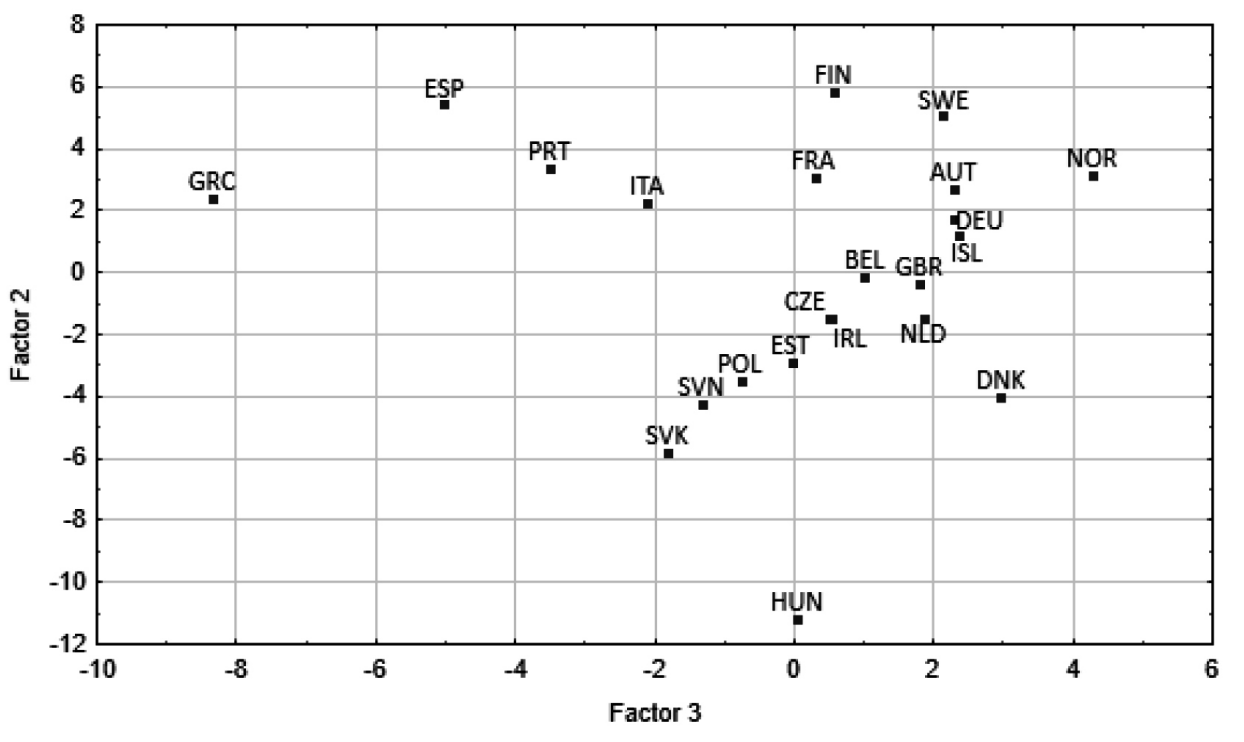

Source: own calculation 
The graphic view of the locations of monitored countries in the coordinate system of the factors $F 1$ and F2 in Fig. 2 and Fig. 3 in visual form allows comparing the social and health levels (Factor 1) as well as mortality on serious diseases (Factor 2) and changes over the 15 years from 2000 to 2015 . Although in the countries of the former socialist bloc there is a noticeably worse social situation and health status than in other European countries in both years, there is a clear positive shift according to both factors. Unsatisfactory situation persists in Hungary; a significant improvement was recorded in Portugal.

In Fig. 4 and Fig. 5 we can see that the decrease in unemployment in Slovakia, Poland, Estonia, Czech Republic and Hungary and the increase of unemployment in Greece, Spain, Portugal and Italy in 2015 compared to 2000 did not cause significant changes in the mortality for serious diseases (Factor 2).

\subsection{Cluster Analysis Results}

The results of cluster analysis by 15 variables are consistent with the results of factor analysis, as we can see from dendrograms on Fig. 6 and Fig. 7, as a results of Ward's Method with Euclidean distance between two different countries in both years 2000 and 2015.

In both years, the countries are divided into two basic clusters that have joined to one cluster at a very long distance. The countries in these two clusters are therefore very different given the observed indicators. The smaller cluster in the year 2000 included only five former socialist countries, Slovakia, Poland, Estonia, Hungary and the Czech Republic. All others countries belonged to second cluster. Slovenia joined the cluster of former socialist countries in 2015. The distance at which this cluster in 2015 associated with cluster of the remaining countries almost unchanged in comparison with 2000. Large cluster of other countries is not homogeneous in 2000 nor in 2015. Visually, in both periods, it consists of three clusters of substantially similar countries. In 2000, one cluster was formed by the Ireland, Denmark, Great Britain, Netherlands and Belgium, another cluster included Slovenia, Portugal, Greece, Spain, Italy and France, and the last cluster consisted

\section{Fig. 6: Dendrogram, Ward's Method, Euclidean distance, standardised data, 2000 (output from Statistica 12)}

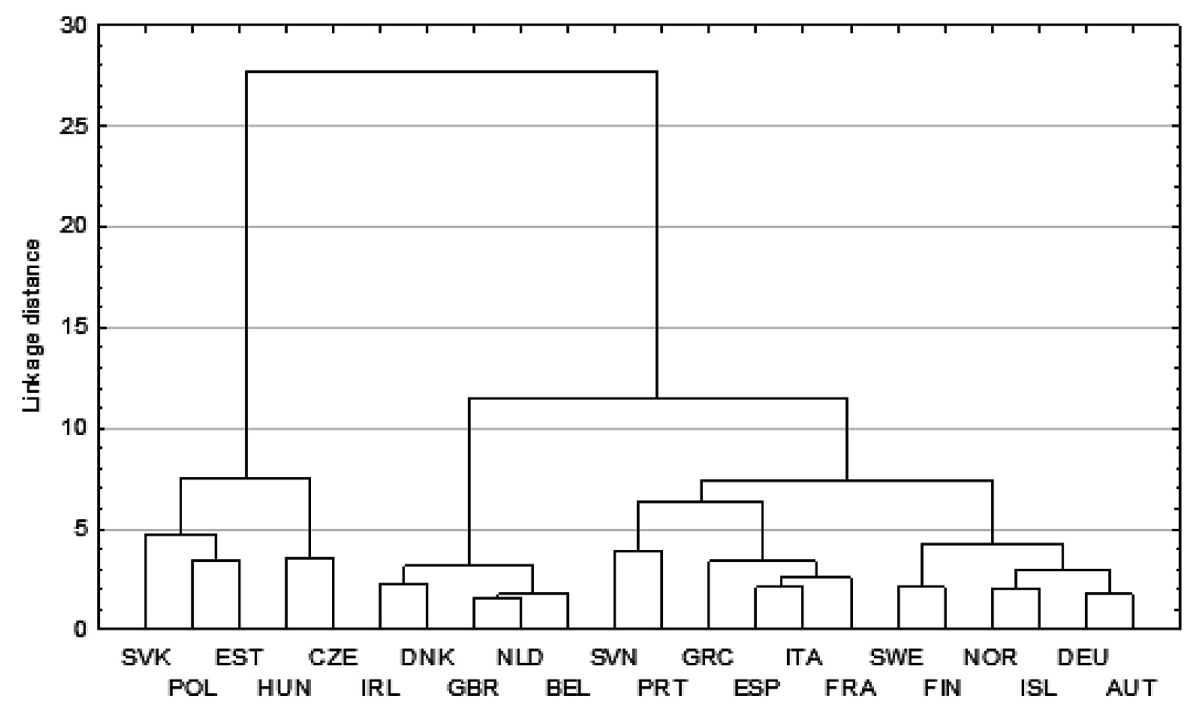




\section{Fig. 7: Dendrogram, Ward's Method, Euclidean distance, standardised data, 2015 (output from Statistica 12)}

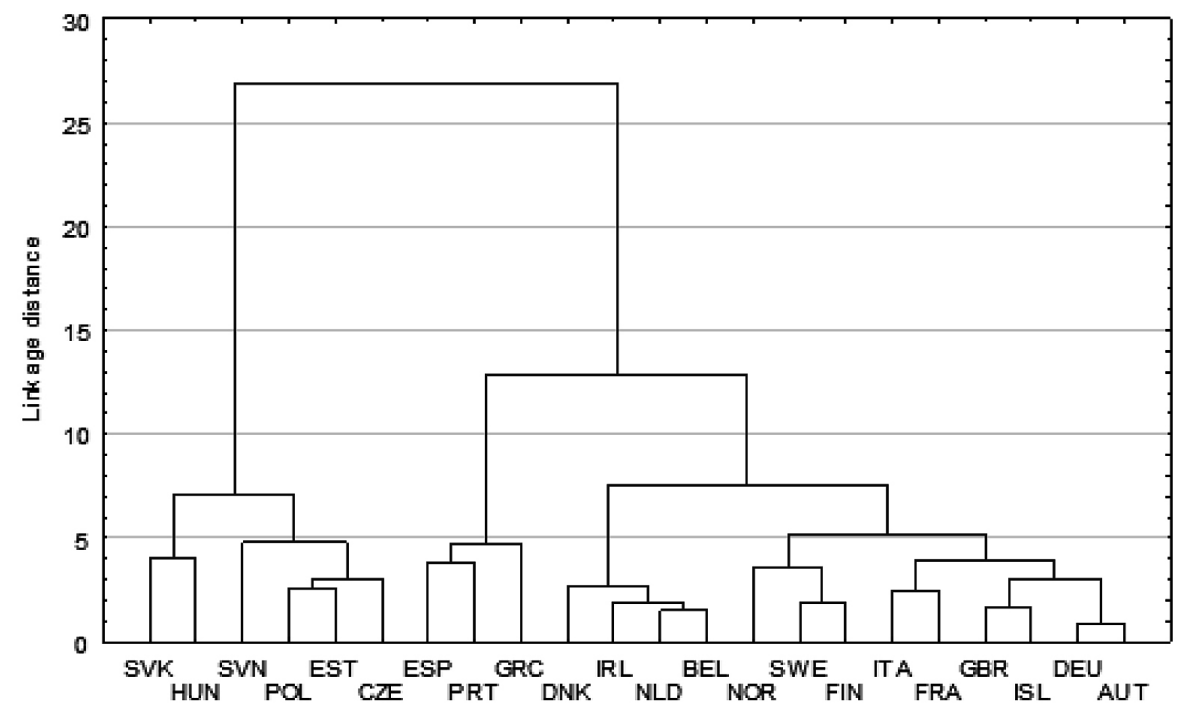

Source: own calculations

of Sweden, Finland, Norway, Iceland, Germany and Austria.

Several changes occurred in the clustering of European countries over 15 year period. The United Kingdom, France and Italy shifted to the cluster of Scandinavian countries, Iceland, Germany and Austria which became the most numerous cluster of nine European countries. The other two clusters are small in number, one consists of three countries, Spain, Portugal and Greece, the second is formed by Denmark, Ireland, the Netherlands and Belgium.

\subsection{Multidimensional Comparative Analysis Results}

Among the 15 variables used in our analysis the variables $D 1, D 2, S 3$ and $S 4$ are apparently stimulants, while the remaining variables are destimulants by subchapter 2.3. We created two synthetic variables in the year 2000 called ScoreH 1 and ScoreS1 and analogous variables called ScoreH2 and ScoreS2 in the year 2015. ScoreH1 and ScoreH2 are the synthetic indicators of health status and synthetic variables ScoreS1, SoreS2 quantify the social situation in monitored European countries.

Synthetic indicators ScoreH1, ScoreH2 in both years were created as the arithmetic average of the standardised original variables M1-M7, C1, C2. Because all these variables are destimulants, we used Formula 3 for standardisation. The synthetic variables ScoreS1, ScoreS2 are the arithmetic means of the standardised indicators $D 1, D 2, S 3$, S4 according to Formula 2 (stimulants), and standardised variables $S 1, \quad S 2$ according to Formula 3 (destimulants). It is clear that the higher is the value of these synthetic variables in European countries, the higher is the social level and the level of health. Finally, the monitored countries in both years were arranged in descending order by ScoreH1, ScoreS1, ScoreH2, and ScoreS2 with assigned rankings from 1 to 22 by level of social situation and quality of health (Tab. 3).

Tab. 4 shows Spearman rank correlations between each pair of synthetic variables in the both years 2000 and 2015 .

The values of Spearman's rank correlation coefficients in Tab. 4 show that in the year 


\begin{tabular}{|c|c|c|c|c|c|c|c|c|}
\hline \multirow{2}{*}{ Country } & \multicolumn{4}{|c|}{2000} & \multicolumn{4}{|c|}{2015} \\
\hline & ScoreH1 & ScoreS1 & RankH1 & RankS1 & ScoreH2 & ScoreS2 & RankH1 & RankS2 \\
\hline Austria & 59.721 & 75.486 & 11 & 4 & 70.124 & 70.928 & 9 & 5 \\
\hline Belgium & 64.895 & 62.124 & 8 & 11 & 71.797 & 61.450 & 6 & 11 \\
\hline Czech Republic. & 44.156 & 43.632 & 21 & 18 & 55.455 & 54.514 & 17 & 13 \\
\hline Denmark & 56.832 & 74.367 & 15 & 5 & 61.378 & 70.580 & 15 & 6 \\
\hline Estonia & 50.610 & 36.669 & 19 & 21 & 52.027 & 51.019 & 19 & 16 \\
\hline Finland & 70.955 & 59.157 & 3 & 12 & 81.273 & 61.674 & 2 & 10 \\
\hline France & 77.908 & 63.716 & 1 & 9 & 82.616 & 62.023 & 1 & 9 \\
\hline Germany & 59.227 & 62.939 & 12 & 10 & 68.407 & 72.089 & 10 & 3 \\
\hline Greece & 70.822 & 51.648 & 4 & 17 & 66.682 & 43.631 & 13 & 22 \\
\hline Hungary & 37.040 & 43.587 & 22 & 19 & 40.085 & 47.097 & 22 & 20 \\
\hline Iceland & 64.420 & 96.127 & 9 & 1 & 70.768 & 85.138 & 8 & 2 \\
\hline Ireland & 53.507 & 66.453 & 16 & 7 & 60.554 & 58.762 & 16 & 12 \\
\hline Italy & 70.466 & 58.651 & 6 & 13 & 71.078 & 54.452 & 7 & 14 \\
\hline Netherlands & 59.216 & 75.723 & 13 & 3 & 68.174 & 66.292 & 12 & 8 \\
\hline Norway & 63.827 & 95.576 & 10 & 2 & 75.365 & 88.769 & 5 & 1 \\
\hline Poland & 51.953 & 37.303 & 18 & 20 & 52.710 & 47.289 & 18 & 19 \\
\hline Portugal & 67.857 & 56.611 & 7 & 14 & 68.359 & 48.419 & 11 & 18 \\
\hline Slovakia & 46.589 & 36.342 & 20 & 22 & 46.400 & 43.809 & 21 & 21 \\
\hline Slovenia & 52.438 & 51.903 & 17 & 16 & 50.636 & 52.428 & 20 & 15 \\
\hline Spain & 70.754 & 52.735 & 5 & 15 & 77.197 & 50.079 & 4 & 17 \\
\hline Sweden & 73.309 & 68.086 & 2 & 6 & 79.510 & 71.020 & 3 & 4 \\
\hline United Kingdom & 58.769 & 65.360 & 14 & 8 & 66.557 & 66.705 & 14 & 7 \\
\hline
\end{tabular}

2000 the degree of compliance in ranks of monitored countries according to the social situation and according to the state of the health was $39.81 \%$, in 2015 it increased to $52.80 \%$. In 2015 , therefore, the social situation in European countries more strongly affected the health status of the population than in 2000 . Compliance in ranks of countries according to the social situation in the years 2000 and 2015 was $88.03 \%$, compliance in ranks according to health status of the same countries in the same years was up to $90.63 \%$. These results do not confirm a significant reduction of inequalities in the social conditions, or in the level of health in European countries in the period between 2000 and 2015. It is remarkable that there is a high degree of compliance in ranks of selected countries according to the state of health in 2015 and according to social situation in 2000 , which is up to $55.05 \%$.

Fig. 8 provides a visual verification of the above mentioned results obtained by multidimensional comparison using synthetic variables. 


\begin{tabular}{l|r|r|r|r} 
& \multicolumn{1}{|c|}{ ScoreH1 } & \multicolumn{1}{c|}{ ScoreS1 } & \multicolumn{1}{c|}{ ScoreH2 } & \multicolumn{1}{c}{ ScoreS2 } \\
\hline ScoreH1 & 1 & 0.3981 & 0.9063 & 0.2772 \\
\hline ScoreS1 & 0.3981 & 1 & 0.5505 & 0.8803 \\
\hline ScoreH2 & 0.9063 & 0.5505 & 1 & 0.5280 \\
\hline ScoreS2 & 0.2772 & 0.8803 & 0.5280 & 1 \\
\hline
\end{tabular}

\section{Fig. 8: Scatterplots matrix (output from Statgraphics Centurion XVII)}

\begin{tabular}{|c|c|c|c|c|}
\hline ScoreH1 & 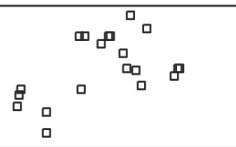 & m & 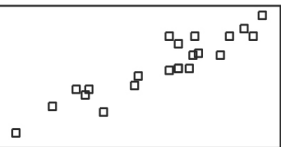 & 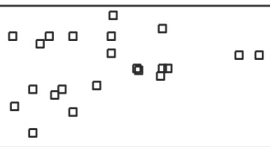 \\
\hline 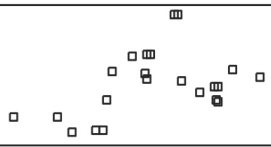 & ScoreS1 & & 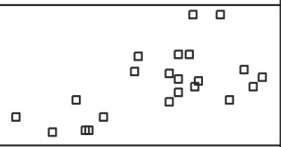 & 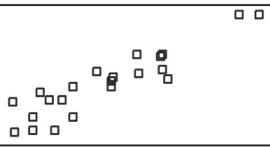 \\
\hline 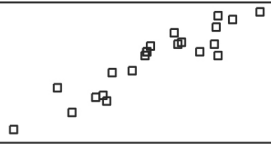 & 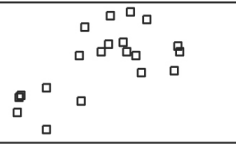 & 品 & ScoreH2 & 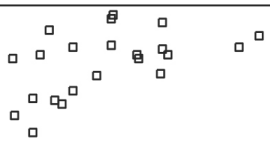 \\
\hline 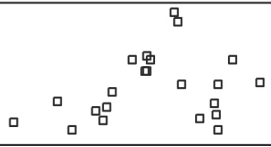 & 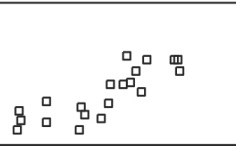 & 要 & 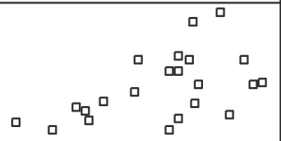 & ScoreS2 \\
\hline
\end{tabular}

Source: own calculations

\section{Conclusion}

Institutions such as the Eurostat, the OECD, and others collect and publish an enormous amount of data that characterize different aspects of countries and regions in Europe. The extensiveness and thus the lack of transparency of said data files is the reason why without adequate statistical analysis is the value of provided information relative low. In the case of large data files, the application of multidimensional statistical methods enable reduced dimension with a minimum loss of information.

Given the uniform method of reporting data for all member states within the Eurostat and the OECD it is possible to use wide range of indicators for comparing European countries on the basis of the health status of inhabitants depending on social and economic situation. The publication of European commission (2015) reflects the 2015 update of the portfolio of EU social indicators covering also the healthcare and long-term care objectives. The indicators are an essential tool to assess the social challenges facing EU countries, identity social trends to watch and support Member States reporting on social policies.

In order to answer the question of whether there is a relationship between the health and social conditions of the population in the European region and quantify its intensity 15 variables were selected. The choice of variables for statistical analysis is always rather subjective until the results of the analysis verify their suitability. 
Based on the data files from the values of the selected 15 variables identified in 22 European countries in the years 2000 and 2015 , and by application of factor, cluster and multidimensional comparative analysis by subchapters 2.1-2.3 the following basic results were obtained. Three common factors were extracted: general factor of social and health situation, factors of mortality for serious diseases and unemployment factor. Together they explained $85.14 \%$ of variability of the original variables in the year 2000 and $84.94 \%$ of variability in the year 2015 .

Given the interrelationship between socioeconomic conditions and the state of health at both individual and country level (Deaton, 2003; Marmot, 2002; Preston, 2007) it is not surprising that a first common factor $(F 1)$ which explains $54.30 \%$ of the total variability in the data in the year 2000 and $54.22 \%$ of the variability in the year 2015, has been interpreted as a general factor of social and health situation due to correlations with the original variables (Tab. 2).

Graphical display of the monitored countries in a coordinate system of common factors confirmed the dependence of health status on the socio-economic situation and noticeably worse social situation and health status in former socialist countries in comparison with other European countries in both years. A positive finding is the reduction of these inequalities in the period between 2000 and 2015 .

The results of cluster analysis are consistent with the results of factor analysis. The results of both multivariate methods are mostly in line with the exiting literature. As discussed in d'Hombres et al. (2013), there is a rich literature dating back to the 1970s, analysing the relationship between income inequality and health (a review of the studies is shown in d'Hombres et al. (2013), Table 5.1). The article of Wilkinson (1992) concludes a negative impact of income inequality on health. However, this view was been challenged by scholars who pointed out strong inconsistencies in the use of data. In particular, the effect of income inequality on health seems to be sensitive to the selected dependent and independent variables included in the analysis, to the methods used for analysis and to the unit of observation (individuals, social or demographic group, region or country).

The synthetic variable of health status and the synthetic variable of the socio-economic situation have made it possible to rank monitored European countries according to both synthetic variables from the "best" to the "worst". The order of countries is shown in Tab. 3. The highest values in order indicating poor social situation and the poor state of health belong to the post-socialist countries of Europe. That could have been expected based on the previous results. Selecting variables for multidimensional comparative analysis of course affects the final order of countries. However, comparative results on the basis of similar indicators can be seen in Sokolowski (1999), Kuc (2012), or Pacáková and Papoušková (2016).

Based on the values of Spearman correlation coefficients in Tab. 4 we conclude that social situation in European countries more strongly affected the health status of the population in the year 2015 than in the year 2000 . The results of multidimensional comparative analysis do not confirm a significant reduction of inequalities in the social conditions, or in the level of health in European countries in the period between 2000 and 2015.

Several cross-country studies for the European countries have provided evidence of inequalities in health outcomes related to socioeconomic variables. However, the causal mechanisms underlying this relationship are complex and controversial (see for example Deaton, 2003; Beckfield \& Krieger, 2009; Jayasinghe, 2015). However, the values of the Spearman correlation coefficients in Tab. 4 which indicate moderately strong dependencies of synthetic indicators of the social situation and the health status of the European countries, are adequate and reasonable.

\section{References}

Beckfield, J., \& Krieger, N. (2009). Epi + demos + cracy: linking political systems and priorities to the magnitude of health inequities - evidence, gaps, and a research agenda. Epidemiologic Reviews, 31(1), 152-177. https://dx.doi.org/10.1093/epirev/mxp002.

Clark, J. S., Dittrich, L. O., Stará, D., \& Barták, M. (2017). The Visit Fees and Its Influence on Overall Health Expenditures - the Case of the Czech Republic. E\&M Ekonomie a Management, 20(2), 4-14. https://dx.doi.org/10.15240/tul/001/2017-2-001.

Deaton, A. (2003). Health, Inequality, and Economic Development. Journal of Economic 
Literature, 41(1), 113-158. https://dx.doi.org/ 10.1257/002205103321544710.

European Commision. (2018). HEALTH Information on policies, strategy and funding in health research and innovation. Retrieved from https://ec.europa.eu/research/health/index.cfm.

European Union. (2013). Improving health for all EU citizens. Luxembourg: Publications Office of the EU. https://dx.doi.org/10.2775/79603.

European Union. (2015). Portfolio of EU Social Indicators for the Monitoring of Progress Towards the EU Objectives for Social Protection and Social Inclusion. Luxembourg: Publications Office of the EU. https://dx.doi. org/10.2767/929097.

Eurostat/European Comission. (2010). Analysing the socioeconomic determinants of health in Europe: new evidence from EU-SILC [Eurostat Methodologies and Working papers]. https://dx.doi.org/10.2785/5478.

Eurostat. (2017). Sustainable development in the European Union. Luxembourg: Publications Office of the EU. https://dx.doi. org/10.2785/237722.

Fitzmaurice, C., Allen, C., Barber, R. M. et al. (2017). Global, regional, and national cancer incidence, mortality, years of life lost, years lived with disability, and disability-adjusted life-years for 32 cancer groups, 1990 to 2015. JAMA Oncology, 3(4), 524-548. https://dx.doi. org/10.1001/jamaoncol.2016.5688.

Gavurová, B., \& Vagasová, T. (2016). Regional differences of standardised mortality rates for ischemic heart diseases in the Slovak Republic for the period 1996-2013 in the context of income inequality. Health Economics Review, 6(21), https://dx.doi.org/10.1186/ s13561-016-0099-1.

Grabiński, T., Wydmus, S., \& Zeliaś, A. (1993). Metody prognozowania rozwoju społecznogospodarczego, Kraków: Wydawnictwo AE.

Hair, J. F., Black, W. C., Babin, B. J., Anderson, R. E., \& Tatham, R. L. (2007). Multivariate Data Analysis (6th ed.). New Jersey: Pearson Education.

Hebák, P., Hustopecký, J., Jarošová, E., I., \& Pecáková, I. (2004). Vícerozměrné statistické metody (Multivariate statistical methods). Praha: Informatorium.

d'Hombres, B., Elia, L., \& Weber, A. (2013). Multivariate analysis of the effect of income inequality on health, social capital, and happiness. Luxembourg: Publication office of the EU. https://dx.doi.org/10.2788/68427.
Jayasinghe, S. (2015). Social determinants of health inequalities: towards a theoretical perspective using systems science. International Journal for Equity in Health. 14(71). https:// dx.doi.org/10.1186/s12939-015-0205-8.

Jindrová, P. (2013). Quantification of Risk in Critical Illness Insurance. In Conference proceedings from 9th international scientific conference Financial Management of Firms and Financial Institutions (pp. 298-306). Ostrava: VŠB Ostrava.

Jindrová, P., \& Kopecká, L. (2017). Assessment of risk factors of serious diseases in OECD countries. In Proceedings of the 11th Professor Aleksander Zelias International Conference on Modelling and Forecasting of Socio-Economic Phenomena (pp. 123-132). Cracow: Cracow University.

Johnson, R. A., \& Wichern, D. W. (2007). Applied Multivariate Statistical Analysis (6th ed.). New Jersey: Pearson Prentice Hall.

Kopecká, L., \& Jindrová, P. (2017). Comparison of Mortality due to Critical Illnesses in the EU Countries. In Proceedings of the 11th Professor Aleksander Zelias International Conference on Modelling and Forecasting of Socio-Economic Phenomena (pp. 133-142). Cracow: Cracow University.

Kuc, M. (2012). The Implementation Of Synthetic Variable For Constructing The Standard Of Living Measure In European Union Countries. Oeconomia copernicana, 3(3), 5-19.

Labudová, V., Vojtková, M., \& Linda, B. (2010). Application of multidimensional methods to measure poverty. E\&M Ekonomie a Management, 13(1), 6-22.

Lundberg, O., Dahl, E., Fritzell, J., Palme, J., \& Sjöberg, O. (2016). Social protection, income and health inequities. WHO Regional Office for Europe. Retrieved from http://www.euro.who. int/_data/assets/pdf_file/0006/302874/TG-GDP_ taxes-income-welfare-final-report.pdf?ua=1.

Marmot, M. G., Shipley, M., \& Rose, G. (1984). Inequalities in Death-Specific Explanations of a General Pattern. Lancet 323(8384), 1003-1006. https://dx.doi. org/10.1016/S0140-6736(84)92337-7.

Marmot, M. G. (2002). The Influence of Income on Health: Views of an Epidemiologist. Health Affairs 21(2), 31-46. https://dx.doi. org/10.1377/hlthaff.21.2.31.

OECD. (2015). Health at a Glance 2015: OECD Indicators. Paris: OECD Publishing. https://dx.doi.org/10.1787/health_glance-2015-en. 
OECD/EU. (2016). Health at a Glance: Europe 2016: State of Health in the EU Cycle. Paris: OECD Publishing. https://dx.doi. org/10.1787/9789264265592-en.

OECD. (2016). Society at a Glance 2016: OECDSociallndicators. Paris:OECDPublishing. https://dx.doi.org/10.1787/9789264261488-en.

Pacáková, V., Jindrová, P., \& Zapletal, D. (2016). Comparison of Health Care Results in Public Health System of European Countries. In European Financial Systems 2016: proceedings of the 13th International Scientific Conference (pp. 534-541). Brno: Masarykova Univerzita.

Pacáková, V., \& Papoušková, M. (2016). Multidimensional Comparisons of Health Systems Functioning in OECD Countries. International Journal of Mathematical Models and Methods in Applied Sciences, 10, 388-394.

Preston, S. H. (2007). The Changing Relation between Mortality and Level of Economic Development. International Journal of Epidemiology, 36(3), 484-490. https://dx.doi. org/10.1093/ije/dym075.

Rodgers, G. B. (1979). Income and Inequality as Determinants of Mortality: An International Cross-section Analysis. Population Studies, 33(2), 343-351. https://dx.doi.org/ 10.1080/00324728.1979.10410449.

Řezánková, H., Húsek, D., \& Snášel, V. (2009). Shluková analýza dat. Praha: Professional Publishing.

Sokolowski, A. (1999). Regional Differences in Living Standards in Eastern European Countries - Changes During the Transition. Research Support Scheme, Open Society Institute. Retrieved from http://rss.archives.ceu. hu/archive/00001052/01/52.pdf.

Staníčková, M. (2015). Classifying the EU Competitiveness Factors Using Multivariate Statistical Methods. Procedia Economics and Finance, 23, 313-320. https://dx.doi. org/10.1016/S2212-5671(15)00508-0.

Stankovičová, I., \& Vojtková, M. (2007). Viacrozmerné štatistické metódy s aplikáciami. Bratislava: lura Edition.

Šoltés, V., \& Gavurová, B. (2014). The Functionality Comparison of the Health Care
Systems by the Analytical Hierarchy Process Method. E\&M Ekonomie a Management, 17(3), 100-117. https://dx.doi.org/10.15240/ tul/001/2014-3-009.

WHO. (2015). WHO Mortality Database. Retrieved from http://www.who.int/healthinfo/ mortality_data/en/.

WHO. (2016). The European health report 2015. Retrieved from http://www.euro. who.int/_data/assets/pdf_file/0006/288645/ European-health-report-2015-full-book-en.pdf.

Wilkins, E., Wilson, L., Wickramasinghe, K., Bhatnagar, P., Leal, J., Luengo-Fernandez, R., Burns, R., Rayner, M., \& Townsend, N. (2017). European Cardiovascular Disease Statistics 2017. Brussels: European Heart Network.

Wilkinson, R. (1992). Income distribution and life expectancy. British Medical Journal, 304(6824), 165-168.

Wilkinson, R. G., \& Pickett, K. E. (2006). Income inequality and population health: a review and explanation of the evidence. Social Science \& Medicine, 62(7), 1768-1784. https://dx.doi.org/10.1016/j.socscimed.2005.08.036.

Wilkinson, R. G., \& Pickett, K. E. (2009). The Spirit Level: Why More Equal Societies Almost Always Do Better. London: Allen Lane. Leadership and Policy in Schools, 11(1), 129-134. https://dx.doi.org/10.1080/15700763. 2011.577928.

prof. RNDr. Viera Pacáková, PhD.

University of Pardubice Faculty of Economics and Administration Institute of Mathematics and Quantitative Methods Czech Republic Viera.Pacakova@upce.cz

Ing. Lucie Kopecká

University of Pardubice

Faculty of Economics and Administration Institute of Mathematics and Quantitative Methods Czech Republic Lucie.Kopecka1@student.upce.cz 


\section{INEQUALITIES IN HEALTH STATUS DEPENDING ON SOCIO-ECONOMIC SITUATION INTHE EUROPEAN COUNTRIES}

\section{Viera Pacáková, Lucie Kopecká}

There are a number of major studies which have demonstrated a clear link between socio-economic background (such as income or occupation) and health. The goal of this article is to assess and quantify inequalities in health status of inhabitants depending on socio-economic situation in European countries based on selected social and health indicators in two different periods. The earlier period is the year 2000, and the later period is the year 2015 or the most recent years. The results of the analysis based on multidimensional statistical methods should give an answer to the question as to whether and how strongly the socio-economic situation in the countries of Europe affects the health status of the population and how the situation has changed over the course of 15 years. In accordance with the stated objectives we have chosen 15 variables (source: WHO, $O E C D$, Eurostat). These variables (indicators) together characterize the quality of life in terms of socio-economic situation and state of health of citizens in 22 selected European countries. The choice of countries was mainly influenced by the availability of data of the selected variables in the both years 2000 and 2015. According to the above mentioned goals of the article we have used factor analysis, cluster analysis and multidimensional comparative analysis methods on data sets of health and socio-economic indicators in the both years. The results of the application of these multidimensional statistical methods, their comparisons and comparisons over time can provide information on whether the targets of the European Commission and the OECD to reduce health inequalities, depending on the socio-economic situation in European countries, in the period from 2000 to 2015 have been achieved.

Key Words: Health, socio-economic situation, inequalities, multidimensional statistical methods.

JEL Classification: 114, 115, C38.

DOI: 10.15240/tul/001/2018-2-001 